\title{
Treatment Patterns in the First Year After Initiating Tumor Necrosis Factor Blockers in Real-World Settings
}

\author{
Machaon Bonafede · Kathleen M. Fox · Crystal Watson · Nicole Princic · Shravanthi R. Gandra
}

To view enhanced content go to www.advancesintherapy.com

Received: May 15, 2012 / Published online: August 8, 2012

(c) The Author(s) 2012. This article is published with open access at Springerlink.com

\section{ABSTRACT}

Background: Tumor necrosis factor (TNF)blockers are approved for use in several immunerelated conditions, but treatment patterns, such as switching between TNF blockers or restarting treatment after a gap in therapy, are not clearly established. This analysis examined TNF blocker treatment patterns within the first year after initiating treatment with etanercept, adalimumab, or infliximab in patients with rheumatoid arthritis, psoriasis, psoriatic arthritis, or ankylosing spondylitis.

M. Bonafede $(\bowtie) \cdot$ N. Princic

Thomson Reuters, 37 Lowell Street, Andover, MA

e-mail: machaon.bonafede@thomsonreuters.com

K. M. Fox

Strategic Healthcare Solutions, LLC, Monkton, MD

C. Watson · S. R. Gandra

Amgen Inc., Thousand Oaks, CA

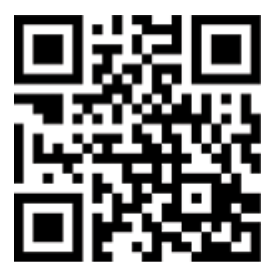

Enhanced content for Advances in Therapy articles is available on the journal web site: www.advancesintherapy.com
Methods: Administrative claims data from the MarketScan ${ }^{\circledR}$ Commercial Claims and Encounters Database (Thomson Reuters, Ann Arbor, MI, USA) were analyzed for patients with rheumatoid arthritis, psoriasis, psoriatic arthritis, or ankylosing spondylitis who were continuously enrolled and newly initiated etanercept, adalimumab, or infliximab treatment between January 1, 2005 and July 1, 2009. Persistence (no treatment gap $\geq 45$ days), restarting index therapy (after a $\geq 45$-day treatment gap), switching to a different biologic of interest (certolizumab, golimumab, ustekinumab, alefacept, abatacept, rituximab, or tocilizumab), and stopping ( $\geq 45$-day treatment gap with no restart or switch) were analyzed for the first year after the index date.

Results: A total of 8,454 patients had an index claim for etanercept $(n=4,224)$, adalimumab $(n=2,941)$, or infliximab $(n=1,289)$. Treatment patterns in the first year across all four conditions combined for etanercept, adalimumab, or infliximab, respectively, were: persistence, $42 \%$, $47 \%$, and $56 \%$; restarting, $25 \%, 19 \%$, and $12 \%$; switching, $13 \%, 12 \%$, and 13\%; and stopping, $20 \%, 22 \%$, and $19 \%$. The combined rates of either persistence or restarting initial therapy after a treatment gap were $67 \%, 66 \%$, and $68 \%$, for etanercept, adalimumab, and infliximab, 
respectively. Most switches (66-92\%) were between the three TNF blockers.

Conclusion: In the first year after initiating TNF blocker therapy, patients often have a $\geq 45$-day treatment gap; however, approximately twothirds of patients are either persistent with or restart their index therapy in the year following TNF blocker initiation.

Keywords: Adalimumab; Ankylosing spondylitis; Etanercept; Infliximab; Psoriasis; Psoriatic arthritis; Rheumatoid arthritis; TNF blocker; Treatment gaps; Treatment patterns

\section{INTRODUCTION}

Tumor necrosis factor (TNF)-blockers play an important role in the treatment of some autoimmune disorders by helping to regulate the body's inflammatory processes and inhibiting progressive structural damage in rheumatoid arthritis (RA) and psoriatic arthritis (PsA). The most widely used TNF blockers are etanercept, adalimumab, and infliximab. Each of these TNF blockers is indicated for use in adults with the following conditions: moderately to severely active RA; chronic, moderate-to-severe plaque psoriasis (PsO); active PsA; and active ankylosing spondylitis (AS). In the controlled setting of prospective clinical studies, etanercept, adalimumab, and infliximab had comparable efficacy for these conditions [1-8]. More than 20 other clinical studies in patients with RA, as reviewed by Scrivo et al. [9], have generally shown that switching to a second TNF blocker after discontinuation of the initial TNF blocker can improve outcomes. However, little is known about the frequency with which patients in realworld settings switch to a second TNF blocker.

Several recent studies have examined adherence and persistence rates for etanercept, adalimumab, and infliximab treatment [10-19].
Two of the studies analyzed rates of switching between TNF blockers [10,11], and others focused on treatment persistence [12-19]. None of the studies analyzed rates of restarting the index TNF blocker after a treatment gap. Additionally, one study included patients with RA, PsA, or AS [19], and others only included patients with RA [10-18]. For medications with several shared indications, such as etanercept, adalimumab, and infliximab, it is important to consider treatment patterns across conditions, particularly because there is evidence that treatment patterns may differ by condition [20]. Additionally, guidelines for the use of TNF blockers in the treatment of RA [21], PsO [22], PsA [23], and AS [24] do not provide clear guidance on restarting treatment or switching to a different biologic. The objective of this analysis was to examine TNF blocker treatment patterns in real-world settings within the first year after initiating treatment with etanercept, adalimumab, or infliximab in patients with RA, PsO, PsA, or AS.

\section{METHODS}

\section{Data Source}

This retrospective analysis used administrative claims data from the MarketScan ${ }^{\circledR}$ Commercial Claims and Encounters Database (Thomson Reuters, Ann Arbor, MI, USA). This database contains the healthcare experience of privately insured individuals covered under a variety of fee-for-service, fully capitated, and partially capitated health plans. The database contains fully adjudicated de-identified medical claims (inpatient, outpatient, emergency room) and outpatient pharmacy claims linked to plan enrollment information provided by large employer-sponsored health plans from across the United States. There are approximately 30 million enrollees per year from more than 100 large employers, including 
administrative claims data on employees, spouses, and dependents.

\section{Study Population}

Patients with at least one claim for a TNF blocker (etanercept, adalimumab, or infliximab) between January 1, 2005 and July 1, 2009 were included in the analysis if they were continuously enrolled in a health plan with medical and pharmacy benefits for at least 180 days before and 360 days following initiation of TNF blocker treatment. The date of the first observed claim for etanercept, adalimumab, or infliximab qualified as the index date. The pre-index period was defined as the 6-month period before the index date. The post-index period was the 12-month period following the index date. The end date for data included in the analysis was June 30, 2010.

Biologic naïve patients were included in the analysis if they were 18-64 years of age on the index date and had at least one claim with a diagnosis code of RA (714.xx), PsO (696.xx, except 696.0x), PsA (696.0x), or AS (720.0x) in the 180-day pre-index period. Patients with International Classification of Diseases, 9th Revision, Clinical Modification (ICD-9-CM) diagnosis codes for more than one of these conditions were not included in this report.

The index date needed to occur within the identification period, which began on the first month by which all three TNF blockers had been approved for use in patients with that condition. Thus, the index date for each condition could occur on the following dates: RA, between January 1 , 2005 and July 1, 2009; PsO, between February 1, 2008 and July 1, 2009; PsA, between November 1, 2005 and July 1, 2009; AS, between 1 August 2006 and 1 July 2009.

Patients were excluded from the analysis if they had a claim for etanercept, adalimumab, infliximab, or a different biologic of interest (certolizumab, golimumab, ustekinumab, alefacept, abatacept, rituximab, and tocilizumab) any time before its FDA market approval for the condition of interest or within the pre-index period, or a claim for more than one of these biologic treatments on the index date. The other biologics were not included as index medications because an insufficient number of patients initiated treatment with these drugs in the study period, but patients who received one of these biologics after the index date were included in analyses of switching to a different biologic of interest. Patients were not considered to have switched to a different biologic of interest if the biologic was not approved for that condition: patients with RA, PsA, or AS who switched to ustekinumab or alefacept; patients with $\mathrm{PsO}$, PsA, or AS who switched to tocilizumab, certolizumab, rituximab, or abatacept; and patients with PsO who switched to golimumab.

\section{Study Measures}

Treatment patterns were evaluated for 360 days after the index date. Persistence with the index TNF blocker within the first year was defined as no treatment gap $\geq 45$ days after the end of estimated clinical benefit for that treatment, which was assumed to be 7 days for each $50 \mathrm{mg}$ syringe of etanercept, 14 days for each $40 \mathrm{mg}$ syringe of adalimumab, and 56 days for each infusion of infliximab. Patients with a treatment gap of $<45$ days at the end of the first year were considered persistent. Restarting treatment within the first year was defined as a $\geq 45$-day treatment gap, followed by a subsequent claim for the index TNF blocker. Switching biologics was defined as a claim for a different biologic of 
interest at any time in the first year after the index date. Stopping treatment was defined as a $\geq 45$-day treatment gap after the end of the estimated clinical benefit, without restarting or switching to another biologic of interest in the first year after the index date.

\section{Data Analysis}

Data were summarized descriptively by condition (RA, PsO, PsA, or AS) and initial TNF blocker (etanercept, adalimumab, or infliximab).
Summaries of data at the index date for initial TNF blocker included patient characteristics (age, sex, geographic location, and plan type) and prescribing physician specialty. Analyses of treatment patterns included the number and percentage of patients who were persistent, restarted the initial TNF blocker after a $\geq 45$-day treatment gap, switched to a different biologic of interest, or stopped the index TNF blocker, as defined above. The time to the switch and drug to which the patient switched were summarized.

Table 1 Baseline characteristics of patients initiating TNF blocker treatment

\begin{tabular}{lccc}
\hline Characteristic & $\begin{array}{c}\text { Etanercept } \\
(\boldsymbol{n}=\mathbf{4 , 2 2 4 )}\end{array}$ & $\begin{array}{c}\text { Adalimumab } \\
(\boldsymbol{n}=\mathbf{2 , 9 4 1 )}\end{array}$ & $\begin{array}{c}\text { Infliximab } \\
(\boldsymbol{n}=\mathbf{1 , 2 8 9})\end{array}$ \\
\hline Age (years), mean (SD) & $48(11)$ & $49(11)$ & $51(10)$ \\
Female, $n$ (\%) & $2,851(68)$ & $1,988(68)$ & $946(73)$ \\
Patient geographic region, $n$ (\%) & & & \\
Northeast & $449(11)$ & $269(9)$ & $137(11)$ \\
Midwest & $1,002(24)$ & $753(26)$ & $256(20)$ \\
South & $2,044(48)$ & $1,541(52)$ & $734(57)$ \\
West & $706(17)$ & $364(12)$ & $158(12)$ \\
Plan type, $n$ (\%) & & & \\
Preferred provider organization & $2,540(60)$ & $1,761(60)$ & $757(59)$ \\
Health maintenance organization & $669(16)$ & $480(16)$ & $221(17)$ \\
Point of service & $526(12)$ & $346(12)$ & $146(11)$ \\
Indemnity plan & $287(7)$ & $216(7)$ & $92(7)$ \\
Other & $105(3)$ & $84(3)$ & $43(3)$ \\
Unknown & $97(2)$ & $54(2)$ & $30(2)$ \\
Prescribing physician specialty, $n$ (\%) & & & \\
Rheumatology & $1,332(32)$ & $958(33)$ & $817(63)$ \\
Internal medicine & $987(23)$ & $723(25)$ & $258(20)$ \\
General practitioner & $382(9)$ & $258(9)$ & $34(3)$ \\
Dermatology & $322(8)$ & $182(6)$ & $5(0)$ \\
Other & $1,134(27)$ & $785(27)$ & $163(13)$ \\
Unknown & $67(2)$ & $35(1)$ & $12(1)$ \\
\hline
\end{tabular}

${ }^{a}$ Prescribing physician specialty was defined using the claim nearest the index claim. The "other" category includes physician not elsewhere classified. If a physician practiced in a multi-physician specialty then the claim was often classified as not elsewhere classified and hence was classified as "other" in this analysis. The patients in the "other" category may have seen a rheumatologist at another time, just not during the visit closest to the index event 


\section{RESULTS}

The study criteria were met in 8,454 patients who newly initiated TNF blocker treatment in the study period. Among patients with RA, PsO, PsA, and AS, the mean (SD) age at baseline was 50 (10), 44 (11), 48 (10), and 43 (12) years, respectively, and 76\%, $46 \%, 50 \%$, and $40 \%$ of patients, respectively, were women. The initial TNF blocker treatment was etanercept in 4,224 (50\%) patients, adalimumab in 2,941 (35\%) patients, and infliximab in 1,289 (15\%) patients. Baseline demographic and clinical characteristics were similar between the three treatment groups (Table 1); in the etanercept, adalimumab, and infliximab groups, respectively, mean (SD) age was 48 (11), 49 (11), and 51 (10) years, and $68 \%, 68 \%$, and $73 \%$ of patients were women.

Treatment patterns for all patients combined are summarized in Fig. 1. For all conditions combined, treatment patterns in the first year after starting etanercept, adalimumab, or infliximab treatment, respectively, were: persistence, $42 \%$, $47 \%$, and 56\%; restarting initial TNF blocker after a $\geq 45$-day treatment gap, $25 \%, 19 \%$, and $12 \%$; switch to a different biologic of interest, $13 \%$, $12 \%$, and $13 \%$; and stop ( $\geq 45$-day treatment gap with no restart or switch), $20 \%, 22 \%$, and $19 \%$. Thus, the combined rates of either persistence or restarting after a treatment gap were $67 \%$, $66 \%$, and $68 \%$ for etanercept, adalimumab, and infliximab, respectively.

Most patients who switched from the index TNF blocker to a different biologic of interest in the first year switched to one of the other index TNF inhibitors (Fig. 1), and the most common switches were between etanercept and adalimumab. Of the patients who switched from etanercept to a different biologic, 73\% switched to adalimumab, $19 \%$ to infliximab, and $8 \%$ to another biologic of interest. Of the patients who switched from adalimumab to a different biologic, $62 \%$ switched to etanercept, $25 \%$ to infliximab, and $13 \%$ to another biologic of interest. Of the patients who switched from infliximab to a different biologic, 31\% switched to etanercept, $36 \%$ to adalimumab, and $34 \%$ to another biologic of interest.
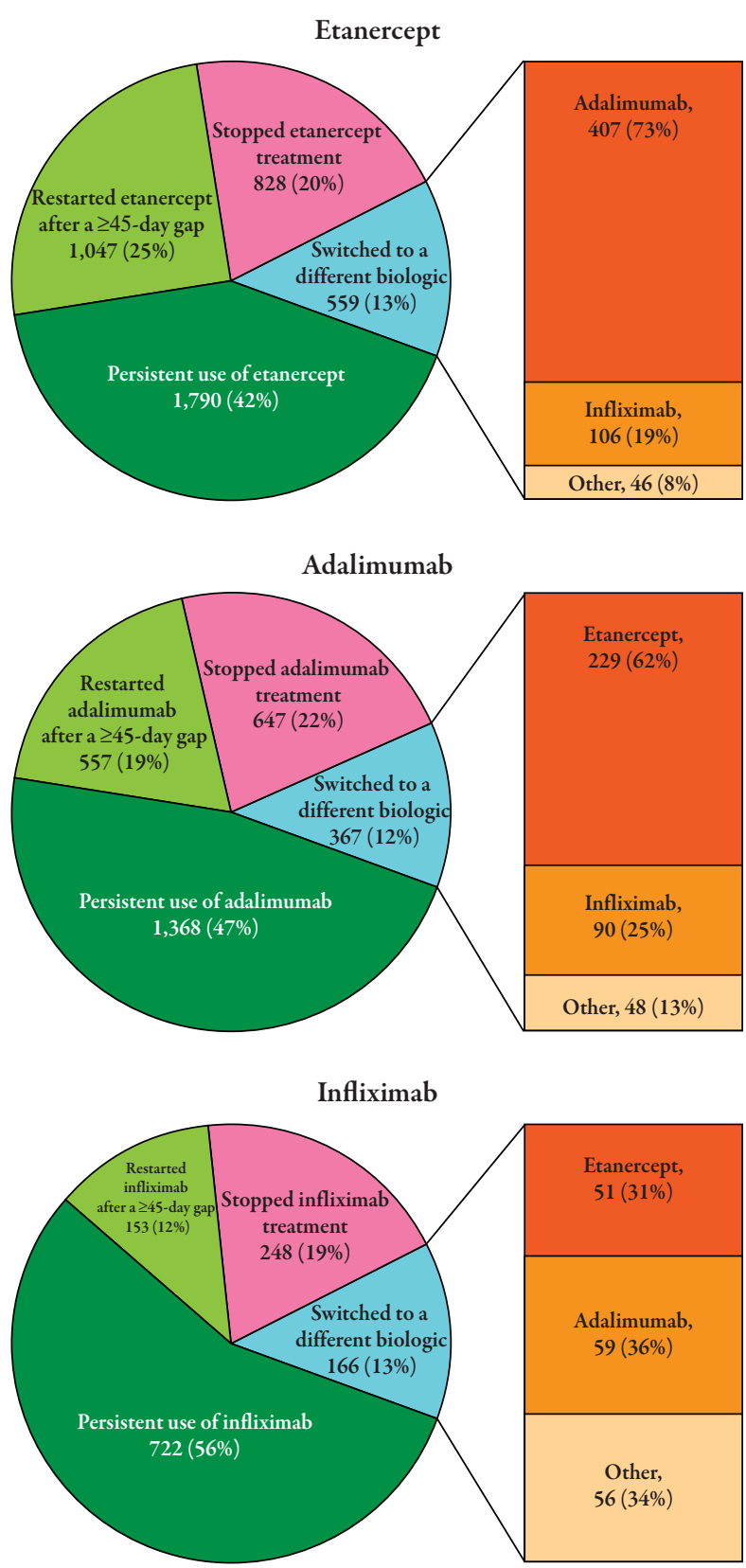

Fig. 1 Treatment patterns in the first year for newly initiated TNF blocker treatment 
Table 2 Treatment patterns in the first year, by condition

\begin{tabular}{|c|c|c|c|}
\hline \multirow[t]{2}{*}{ Treatment pattern in the first year } & \multicolumn{3}{|c|}{ No. (\%) of patients } \\
\hline & Etanercept & Adalimumab & Infliximab \\
\hline Rheumatoid arthritis & $(n=2,933)$ & $(n=2,094)$ & $(n=1,099)$ \\
\hline Persistent use (no switch or $\geq 45$-day gap)a & $1,317(45)$ & $1,003(48)$ & $624(57)$ \\
\hline Restart (after $\geq 45$-day gap) & $675(23)$ & $387(18)$ & $122(11)$ \\
\hline Switch to & $446(15)$ & $294(14)$ & $146(13)$ \\
\hline Etanercept & - & $181(9)$ & $42(4)$ \\
\hline Adalimumab & $308(11)$ & - & $52(5)$ \\
\hline Infliximab & $95(3)$ & $69(3)$ & - \\
\hline Other biologic of interest ${ }^{\mathrm{b}}$ & $43(1)$ & $44(2)$ & $52(5)$ \\
\hline Stop ( $\geq 45$-day gap, no restart or switch) & $495(17)$ & $410(20)$ & $207(19)$ \\
\hline Psoriasis & $(n=545)$ & $(n=318)$ & $(n=11)$ \\
\hline Persistent use (no switch or $\geq 45$-day gap)a & $121(22)$ & $105(33)$ & $4(36)$ \\
\hline Restart (after $\geq 45$-day gap) & $176(32)$ & $76(24)$ & $1(9)$ \\
\hline Switch to & $39(7)$ & $18(6)$ & $1(9)$ \\
\hline Etanercept & - & $9(3)$ & $0(0)$ \\
\hline Adalimumab & $35(6)$ & - & $1(9)$ \\
\hline Infliximab & $2(<1)$ & $5(2)$ & - \\
\hline Other biologic of interest ${ }^{\mathrm{b}}$ & $2(<1)$ & $4(1)$ & $0(0)$ \\
\hline Stop ( $\geq 45$-day gap, no restart or switch) & $209(38)$ & $119(37)$ & $5(45)$ \\
\hline Psoriatic arthritis & $(n=597)$ & $(n=426)$ & $(n=133)$ \\
\hline Persistent use (no switch or $\geq 45$-day gap) & $281(47)$ & $225(53)$ & $75(56)$ \\
\hline Restart (after $\geq 45$-day gap) & $172(29)$ & $73(17)$ & $23(17)$ \\
\hline Switch to & $62(10)$ & $46(11)$ & $13(10)$ \\
\hline Etanercept & - & $33(8)$ & $5(4)$ \\
\hline Adalimumab & $52(9)$ & - & $4(3)$ \\
\hline Infliximab & $9(2)$ & $13(3)$ & - \\
\hline Other biologic of interest ${ }^{\mathrm{b}}$ & $1(<1)$ & $0(0)$ & $4(3)$ \\
\hline Stop ( $\geq 45$-day gap, no restart or switch) & $82(14)$ & $82(19)$ & $22(17)$ \\
\hline Ankylosing spondylitis & $(n=149)$ & $(n=103)$ & $(n=46)$ \\
\hline Persistent use (no switch or $\geq 45$-day gap)a & $71(48)$ & $35(34)$ & $19(41)$ \\
\hline Restart (after $\geq 45$-day gap) & $24(16)$ & $21(20)$ & $7(15)$ \\
\hline Switch to & $12(8)$ & $11(11)$ & $6(13)$ \\
\hline Etanercept & - & $6(6)$ & $4(9)$ \\
\hline Adalimumab & $12(8)$ & - & $2(4)$ \\
\hline Infliximab & $0(0)$ & $3(3)$ & - \\
\hline Other biologic of interest ${ }^{\mathrm{b}}$ & $0(0)$ & $0(0)$ & $0(0)$ \\
\hline Stop ( $\geq 45$-day gap, no restart or switch) & $42(28)$ & $36(35)$ & $14(30)$ \\
\hline
\end{tabular}

${ }^{\text {a }}$ Patients with a treatment gap of $<45$ days at the end of the first year were counted in this row

${ }^{\mathrm{b}}$ Certolizumab, golimumab, ustekinumab, alefacept, tocilizumab, abatacept, or rituximab 
Treatment patterns are summarized by treatment and condition in Table 2 . Patients with RA comprised $72 \%$ of the study population, and treatment patterns by TNF blocker treatment group in these patients were generally consistent with those of the overall study population. Among patients with RA, treatment patterns in the first year after starting etanercept, adalimumab, or infliximab treatment, respectively, were: persistence, $45 \%$,
48\%, 57\%; restarting initial TNF blocker after a $\geq 45$-day treatment gap, $23 \%, 18 \%$, and $11 \%$; switch to a different biologic of interest, $15 \%$, $14 \%$, and $13 \%$; and stop ( $\geq 45$-day treatment gap with no restart or switch), 17\%, 20\%, and 19\%. Thus, the combined rates of either persistence or restarting initial TNF blocker treatment after a treatment gap among patients with RA were $68 \%, 66 \%$, and $68 \%$ for etanercept, adalimumab, and infliximab, respectively.

Table 3 Time from index date to restart of initial TNF blocker or switch to a different biologic of interest

\begin{tabular}{|c|c|c|c|}
\hline & \multicolumn{3}{|c|}{ Mean ( \pm SD) time, days; no. of patients } \\
\hline & Etanercept & Adalimumab & Infliximab \\
\hline Rheumatoid arthritis & $(n=2,933)$ & $(n=2,094)$ & $(n=1,099)$ \\
\hline Time to restart & $219 \pm 79 ; n=675$ & $223 \pm 82 ; n=387$ & $240 \pm 77 ; n=122$ \\
\hline \multicolumn{4}{|l|}{ Time to switch to } \\
\hline Etanercept & - & $184 \pm 90 ; n=181$ & $207 \pm 96 ; n=42$ \\
\hline Adalimumab & $183 \pm 91 ; n=308$ & - & $170 \pm 85 ; n=52$ \\
\hline Infliximab & $174 \pm 88 ; n=95$ & $178 \pm 78 ; n=69$ & - \\
\hline Psoriasis & $(n=545)$ & $(n=318)$ & $(n=11)$ \\
\hline Time to restart & $226 \pm 80 ; n=176$ & $230 \pm 83 ; n=76$ & $9 ; n=1$ \\
\hline \multicolumn{4}{|l|}{ Time to switch to } \\
\hline Etanercept & - & $137 \pm 84 ; n=9$ & $\mathrm{NA} ; n=0$ \\
\hline Adalimumab & $208 \pm 96 ; n=35$ & - & $342 ; n=1$ \\
\hline Infliximab & $344 \pm 22 ; n=2$ & $130 \pm 130 ; n=5$ & - \\
\hline Psoriatic arthritis & $(n=597)$ & $(n=426)$ & $(n=133)$ \\
\hline Time to restart & $230 \pm 81 ; n=172$ & $233 \pm 85 ; n=73$ & $263 \pm 75 ; n=23$ \\
\hline \multicolumn{4}{|l|}{ Time to switch to } \\
\hline Etanercept & - & $213 \pm 83 ; n=33$ & $123 \pm 50 ; n=5$ \\
\hline Adalimumab & $192 \pm 87 ; n=52$ & - & $147 \pm 112 ; n=4$ \\
\hline Infliximab & $133 \pm 47 ; n=9$ & $197 \pm 91 ; n=13$ & - \\
\hline Ankylosing spondylitis & $(n=149)$ & $(n=103)$ & $(n=46)$ \\
\hline Time to restart & $206 \pm 92 ; n=24$ & $211 \pm 84 ; n=21$ & $261 \pm 57 ; n=7$ \\
\hline \multicolumn{4}{|l|}{ Time to switch to } \\
\hline Etanercept & - & $153 \pm 72 ; n=6$ & $169 \pm 128 ; n=4$ \\
\hline Adalimumab & $175 \pm 56 ; n=12$ & - & $67 \pm 4 ; n=2$ \\
\hline Infliximab & $\mathrm{NA} ; n=0$ & $173 \pm 75 ; n=3$ & - \\
\hline
\end{tabular}

$n$ values are provided for the full group of patients with that condition and index TNF blocker; mean $( \pm$ SD) values were calculated among the patients who restarted or switched $N A$ not applicable (no patients switched), $T N F$ tumor necrosis factor 
Among patients with PsO (Table 2), treatment patterns in the first year after starting etanercept, adalimumab, or infliximab treatment, respectively, were: persistence, 22\%, 33\%, 36\%; restarting initial TNF blocker after a $\geq 45$-day treatment gap, $32 \%, 24 \%$, and $9 \%$; switch to a different biologic of interest, 7\%, 6\%, and 9\%; and stop ( $\geq 45$-day treatment gap with no restart or switch), 38\%, 37\%, and $45 \%$. Thus, combined rates of either persistence or restarting after a treatment gap among patients with $\mathrm{PsO}$ were $54 \%, 57 \%$, and $45 \%$ for etanercept, adalimumab, and infliximab, respectively.

Among patients with PsA (Table 2), treatment patterns in the first year after starting etanercept, adalimumab, or infliximab treatment, respectively, were: persistence, 47\%, 53\%, 56\%; restarting initial TNF blocker after a $\geq 45$-day treatment gap, $29 \%, 17 \%$, and $17 \%$; switch to a different biologic of interest, 10\%, 11\%, and $10 \%$; and stop ( $\geq 45$-day treatment gap with no restart or switch), $14 \%, 19 \%$, and $17 \%$. Thus, the combined rates of either persistence or restarting after a treatment gap among patients with PsA were $76 \%, 70 \%$, and $73 \%$ for etanercept, adalimumab, and infliximab, respectively.

Among patients with AS (Table 2), treatment patterns in the first year after starting etanercept, adalimumab, or infliximab treatment, respectively, were: persistence, 48\%, 34\%, 41\%; restarting initial TNF blocker after a $\geq 45$-day treatment gap, $16 \%, 20 \%$, and $15 \%$; switch to a different biologic of interest, $8 \%, 11 \%$, and $13 \%$; and stop ( $\geq 45$-day treatment gap with no restart or switch), $28 \%, 35 \%$, and 30\%. Thus, combined rates of either persistence or restarting after a treatment gap among patients with AS were $64 \%, 54 \%$, and $56 \%$ for etanercept, adalimumab, and infliximab, respectively.

Table 3 summarizes the time from the index date to restarting the index TNF blocker or switching to a different TNF blocker.
Among patients with RA, the mean (SD) time to restarting the index TNF blocker was 219 (79) days for etanercept, 223 (82) days for adalimumab, and 240 (77) days for infliximab. Similar values were seen between treatment groups for the time to restarting the index TNF blocker in patients with $\mathrm{PsO}, \mathrm{PsA}$, or AS; the only exception was the time to restart infliximab in $\mathrm{PsO}$, but this value was based on only one patient who restarted treatment. Mean times to switching from the index TNF blocker to one of the other two indexeligible TNF blockers ranged from 170 to 207 days among patients with RA, from 137 to 342 days among patients with $\mathrm{PsO}$, from 123 to 213 days among patients with PsA, and from 67 to 175 days among patients with AS.

\section{DISCUSSION}

In this analysis of patients with RA, PsO, PsA, or AS initiating a TNF blocker from real-world settings in the United States, etanercept was the most commonly prescribed initial TNF blocker (50\%), followed by adalimumab (35\%) and infliximab (15\%). In the first year after starting TNF blocker treatment, approximately twothirds of patients either were persistent with their index TNF blocker, or restarted treatment with their index TNF blocker after a $\geq 45$-day treatment gap, regardless of the index TNF blocker $(67 \%, 66 \%$, and $68 \%$ for etanercept, adalimumab, and infliximab, respectively). The other patients either switched to a different biologic (13\%) or they stopped TNF blocker treatment without restarting or switching to a different TNF blocker (20\%).

A key aspect of this analysis was the inclusion of patients with one of four conditions in a large, nationwide database. This approach enhanced the generalizability of the results to formulary decisions and payers who are interested in treatment patterns after the initiation of TNF 
blocker treatment among patients with a variety of conditions. It also provided insight into treatment patterns for each of the specific conditions. Although the rates varied by condition, they were similar between etanercept, adalimumab, and infliximab within each condition and across all conditions combined.

A previous analysis of 6,739 patients with RA in a British registry reported that over a mean of 15 months, 856 (13\%) patients switched to a second agent, and $73 \%$ of these patients remained on the second agent at the end of follow-up [10]. A recent retrospective analysis of a commercial database evaluated dosing and discontinuation rates for TNF blocker treatment in 3,217 patients with RA [11]. For the first TNF blocker treatment, the percentage of patients who stopped treatment (defined as a $\geq 60$-day treatment gap or a switch to non-index biologic treatment) was $50 \%$ for etanercept, $53 \%$ for adalimumab, and 40\% for infliximab [11]. However, because "stopping treatment" in that study included all patients with a treatment gap of $\geq 60$ days, it is likely that many of the patients subsequently restarted their index TNF blocker treatment. The other previous studies comparing treatment patterns for TNF blockers focused on compliance and persistence and were either restricted to patients with RA [10-18] or did not include patients with PsO [19]. A literature search identified no previous studies that evaluated treatment patterns across all four conditions or included restarting the index TNF blocker after a treatment gap.

A possible limitation of this analysis was that it used claims data, which do not capture the reason for discontinuation of TNF blocker treatment. Thus, it is unknown whether factors such as physician beliefs or patient beliefs, tolerability, or efficacy contributed to gaps in treatment, stopping treatment, or switching to a different biologic of interest. Likewise, this analysis required 12 months of continuous medical and pharmacy enrollment following treatment initiation, effectively limiting the analysis to patients with health insurance for one year following TNF blocker initiation. As a result, loss of health insurance could not be evaluated as a potential reason for discontinuation. This study was designed to include data for commercial health coverage only, and may not be generalizable to Medicare or other noncommercial populations.

In summary, across four different conditions, patients often have treatment gaps in the first year after initiating TNF blocker treatment with etanercept, adalimumab, or infliximab. Thus, when looking at treatment patterns, it is important to consider the contribution of restarting index therapy after a treatment gap. Approximately two-thirds of patients are persistent or restart index therapy after a treatment gap and the percentages are similar between etanercept, adalimumab, and infliximab, both across the four conditions and within each condition. When patients switch to another biologic treatment, they usually switch to one of these three TNF blockers, rather than to other biologics. Further research is needed to assess whether treatment gaps influence effectiveness.

\section{ACKNOWLEDGMENTS}

This research was funded by Immunex Corporation, a wholly owned subsidiary of Amgen Inc., and by Wyeth, which was acquired by Pfizer Inc. in October 2009.

Dr. Bonafede is the guarantor for this article, and takes responsibility for the integrity of the work as a whole. Jonathan Latham (PharmaScribe, LLC on behalf of Amgen) and Dikran Toroser (Amgen) provided assistance in the drafting of this manuscript. 
Conflict of Interest. Shravanthi R. Gandra is an employee of Amgen and has received Amgen stock/stock options. Crystal Watson was an employee of Amgen and received Amgen stock/ stock options. Machaon Bonafede and Nicole Princic are employees of Thomson Reuters, which received a research contract to conduct this analysis. Kathleen M. Fox received research funds from Amgen as a consultant.

Open Access. This article is distributed under the terms of the Creative Commons Attribution Noncommercial License which permits any noncommercial use, distribution, and reproduction in any medium, provided the original author(s) and source are credited

\section{REFERENCES}

1. Alonso-Ruiz A, Pijoan JI, Ansuategui E, Urkaregi A, Calabozo M, Quintana A. Tumor necrosis factor alpha drugs in rheumatoid arthritis: systematic review and metaanalysis of efficacy and safety. BMC Musculoskelet Disord. 2008;9:52.

2. Donahue KE, Gartlehner G, Jonas DE, et al. Systematic review: comparative effectiveness and harms of disease-modifying medications for rheumatoid arthritis. Ann Intern Med. 2008;148:124-34.

3. Kristensen LE, Christensen R, Bliddal H, Geborek P, Danneskiold-Samsoe B, Saxne T. The number needed to treat for adalimumab, etanercept, and infliximab based on ACR50 response in three randomized controlled trials on established rheumatoid arthritis: a systematic literature review. Scand J Rheumatol. 2007;36:411-17.

4. Singh JA, Christensen R, Wells GA, et al. A network meta-analysis of randomized controlled trials of biologics for rheumatoid arthritis: a Cochrane overview. CMAJ. 2009;181:787-96.

5. Bansback N, Sizto S, Sun H, Feldman S, Willian MK, Anis A. Efficacy of systemic treatments for moderate to severe plaque psoriasis: systematic review and meta-analysis. Dermatology. 2009;219:209-18.

6. Schmitt J, Zhang Z, Wozel G, Meurer M, Kirch W. Efficacy and tolerability of biologic and nonbiologic systemic treatments for moderateto-severe psoriasis: meta-analysis of randomized controlled trials. Br J Dermatol. 2008;159:513-26.
7. Saad AA, Symmons DP, Noyce PR, Ashcroft DM. Risks and benefits of tumor necrosis factoralpha inhibitors in the management of psoriatic arthritis: systematic review and metaanalysis of randomized controlled trials. J Rheumatol. 2008;35:883-90.

8. McLeod C, Bagust A, Boland A, et al. Adalimumab, etanercept and infliximab for the treatment of ankylosing spondylitis: a systematic review and economic evaluation. Health Technol Assess. 2007;11:1-158, iii-iv.

9. Scrivo R, Conti F, Spinelli FR, et al. Switching between TNFalpha antagonists in rheumatoid arthritis: personal experience and review of the literature. Reumatismo. 2009;61:107-17.

10. Hyrich KL, Lunt M, Watson KD, Symmons DP, Silman AJ. Outcomes after switching from one anti-tumor necrosis factor alpha agent to a second anti-tumor necrosis factor alpha agent in patients with rheumatoid arthritis: results from a large UK national cohort study. Arthritis Rheum. 2007;56:13-20.

11. Ogale S, Hitraya E, Henk HJ. Patterns of biologic agent utilization among patients with rheumatoid arthritis: a retrospective cohort study. BMC Musculoskelet Disord. 2011;12:204.

12. Kristensen LE, Saxne T, Nilsson JA, Geborek P. Impact of concomitant DMARD therapy on adherence to treatment with etanercept and infliximab in rheumatoid arthritis. Results from a six-year observational study in southern Sweden. Arthritis Res Ther. 2006;8:R174.

13. Kievit W, Adang EM, Fransen J, et al. The effectiveness and medication costs of three antitumour necrosis factor alpha agents in the treatment of rheumatoid arthritis from prospective clinical practice data. Ann Rheum Dis. 2008;67:1229-34.

14. Du Pan SM, Dehler S, Ciurea A, Ziswiler HR, Gabay C, Finckh A. Comparison of drug retention rates and causes of drug discontinuation between anti-tumor necrosis factor agents in rheumatoid arthritis. Arthritis Rheum. 2009;61:560-8.

15. Marchesoni A, Zaccara E, Gorla R, et al. TNF-alpha antagonist survival rate in a cohort of rheumatoid arthritis patients observed under conditions of standard clinical practice. Ann N Y Acad Sci. 2009; 1173:837-46.

16. Strangfeld A, Hierse F, Kekow J, et al. Comparative effectiveness of tumour necrosis factor alpha inhibitors in combination with either methotrexate or leflunomide. Ann Rheum Dis. 2009;68:1856-62. 
17. Hetland ML, Christensen IJ, Tarp U, et al. Direct comparison of treatment responses, remission rates, and drug adherence in patients with rheumatoid arthritis treated with adalimumab, etanercept, or infliximab: results from eight years of surveillance of clinical practice in the nationwide Danish DANBIO registry. Arthritis Rheum. 2010;62:22-32.

18. Gomez-Reino JJ, Rodriguez-Lozano C, CamposFernandez C, Montoro M, Descalzo MA, Carmona L. Change in the discontinuation pattern of tumour necrosis factor antagonists in rheumatoid arthritis over 10 years: data from the Spanish registry BIOBADASER 2.0. Ann Rheum Dis. 2012;71:382-5.

19. Heiberg MS, Koldingsnes W, Mikkelsen K, et al. The comparative one-year performance of antitumor necrosis factor alpha drugs in patients with rheumatoid arthritis, psoriatic arthritis, and ankylosing spondylitis: results from a longitudinal, observational, multicenter study. Arthritis Rheum. 2008;59:234-40.

20. Carmona L, Gomez-Reino JJ. Survival of TNF antagonists in spondylarthritis is better than in rheumatoid arthritis. Data from the Spanish registry BIOBADASER. Arthritis Res Ther. 2006;8:R72.
21. Saag KG, Teng GG, Patkar NM, et al. American College of Rheumatology 2008 recommendations for the use of nonbiologic and biologic diseasemodifying antirheumatic drugs in rheumatoid arthritis. Arthritis Rheum. 2008;59:762-84.

22. Menter A, Gottlieb A, Feldman SR, et al. Guidelines of care for the management of psoriasis and psoriatic arthritis: Section 1. Overview of psoriasis and guidelines of care for the treatment of psoriasis with biologics. J Am Acad Dermatol. 2008;58:826-50.

23. Gottlieb A, Korman NJ, Gordon $\mathrm{KB}$, et al. Guidelines of care for the management of psoriasis and psoriatic arthritis: Section 2. Psoriatic arthritis: overview and guidelines of care for treatment with an emphasis on the biologics. J Am Acad Dermatol. 2008;58:851-64.

24. Braun J, Pham T, Sieper J, et al. International ASAS consensus statement for the use of anti-tumour necrosis factor agents in patients with ankylosing spondylitis. Ann Rheum Dis. 2003;62:817-24. 